Duong et. al (preprint). A review of robotics and autonomous systems in the food industry: From the supply chains perspective. Trends in Food Science \& Technology. https://doi.org/10.1016/j.tifs.2020.10.028

\title{
A review of Robotics and Autonomous Systems in the food industry: From the supply chains perspective
}

Linh N K Duong ${ }^{1 *}$; Mohammed Al-Fadhli'; Sandeep Jagtap ${ }^{2}$; Farah Bader ${ }^{3}$; Wayne Martindale $^{1}$; Mark Swainson ${ }^{1}$; Andrea Paoli ${ }^{1}$

1. National Centre for Food Manufacturing, University of Lincoln, United Kingdom

2. School of Aerospace, Cranfield University, United Kingdom

3. School of Mechanical, Electrical and Manufacturing Engineering, Loughborough University, United Kingdom

* Corresponding author: 1duong@lincoln.ac.uk

\section{Abstract}

Background

An increasing global population means resource utilisation and food security remain the critical global challenges. Robotics and autonomous systems (RAS) have been applied to improve productivity, and their role in enhancing supply chain operations is explored here.

Scope and approach

Researchers have studied ways to adopt and integrate RAS into the food industry. However, most of the current literature focuses on the technological impact of RAS. In contrast, this paper discusses the adoption of RAS in the food industry from the supply chain perspective with regard to the supply chain operations.

Key findings and conclusions

The study has selected 54 papers using a nine-step systematic review process. This research analysed the use of RAS across five major themes of the food supply chain, including food quality, food safety, food waste, supply chain efficiency, and supply chain analysis. The role of RAS, the data availability, cybersecurity, skill capability, and financial costs are discussed in the context of adopting RAS in food supply chains. Future research directions are proposed with the aim of enhancing the application of RAS in food supply chain operations.

Keywords: food supply chains; robotics and autonomous systems; literature review

\section{Introduction}

The food industry, as recognised by many of the Sustainable Development Goals, has a crucial role in providing food and beverage products. Food crises result in the variable access to 
Duong et. al (preprint). A review of robotics and autonomous systems in the food industry: From the supply chains perspective. Trends in Food Science \& Technology. https://doi.org/10.1016/j.tifs.2020.10.028

appropriate quality and quantities of food and nutrition, and this is identified as a global risk in society (World Economic Forum, 2020). The increases in the global population and personal incomes in developing countries will increase food demand by $59 \%$ to $98 \%$ by 2050 (Elferink $\&$ Schierhorn, 2016). This calls for a focus on improving productivity through the adoption of new technologies such as robotics and autonomous systems (RAS) (Rehman et al., 2019).

RAS is not a new concept, and it is used in the tourism industry for checking in or delivering goods (Ivanov et al., 2019), in the construction industry for the production of high-rise buildings (Cai et al., 2019), and in transport with self-driving trucks (Sanders et al., 2019). In the agri-food industry, the term "Agri-food 3.0", emerged at the end of the twentieth century, refers to RAS (Miranda et al., 2019). Examples of applications include automated milking systems (Driessen \& Heutinck, 2015) and on-farm surveillance systems such as soil moisture monitoring systems (Fentanes et al., 2020). The development of RAS has been encouraged by it being (i) deployable in dangerous areas, (ii) providing high efficiency, (iii) delivering costeffective solutions, (iv) avoiding employee fatigue, or (v) supporting co-working with operators (McCarthy et al., 2018).

Suprem et al. (2013) reviewed technologies adopted in the food industry and emphasised key attributes for their applications. Bouzembrak et al. (2019) investigated the technologies and capabilities for the use of the Internet of Things in food safety, emphasising that their use is a promising area to cope with challenges in the food supply chain. Lezoche et al. (2020) reviewed technologies and supply chain decision-making processes in the food industry; their research enhanced understanding of the future direction of the food industry. Each of these studies focused on applications of RAS from the technological perspectives and analysed future trends for their development.

In contrast to these studies, this research analyses the development of RAS from the whole supply chain perspective. It seeks to address the following questions: what are key applications of RAS in the food supply chain, what are issues of the RAS adoption from the supply chain perspective, and what are future trends in the field of RAS? This will contribute to the literature of RAS in food supply chains becoming complex due to increased collaboration and globalisation (Duong \& Chong, 2020; Zhong et al., 2017). A focus will be shifted from a single echelon (e.g. manufacturers) to the holistic view of supply chains (Grimm et al., 2014). This shift is beneficial in identifying new ways of creating business strategies and deliverables (Kavadias \& Ulrich, 2020). It will also enhance the evaluation of RAS implementation, which should not be evaluated based on criteria set by a taken perspective (Serra \& Kunc, 2015). In 
Duong et. al (preprint). A review of robotics and autonomous systems in the food industry: From the supply chains perspective. Trends in Food Science \& Technology. https://doi.org/10.1016/j.tifs.2020.10.028

doing this with RAS from a supply chain perspective, this research offers opportunities for designing a comprehensive evaluation framework in the food industry (Sterman et al., 2015). As such, the reflective analysis developed can provide opportunities to enhance the impacts of RAS and provide insights for targeted research in the future (Kavadias \& Ulrich, 2020).

This describes the platform position of the paper, creating a transition from operations to supply chains. The other sections are organised as follows; section 2 reviews the literature relating to RAS; section 3 introduces the research methodology. Thematic analyses and discussion are presented in section 4 and 5. Section 6 concludes the research summary using targeted future projections.

\section{Literature review}

The food industry is dependent on human resources with limited use of machinery and increased demand, global competition and advanced technologies have facilitated the utilisation of RAS in the agri-food industry (Rehman et al., 2019). RAS is used across a wide spectrum of applications within the food industry with the main ones classified as follows.

\subsection{Harvesters and agri-robots}

Harvesting is an important stage of agricultural production; it is considered a core agricultural activity and most of the fruit harvesting is still carried out manually (Suprem et al., 2013). Fruit picking robots have been developed with vision processing capabilities and utilise several picking mechanisms (Bloch et al., 2018). Researchers have investigated and developed methods of using RAS for fruit harvesting (Bogue, 2020). RAS harvesting applications for greenhouses have been developed where it is easier to move robots inside closed environments (Bloch et al., 2018). The utilisation of the RAS is increasing in these operations, and it is projected to be used in $20 \%$ of future harvesting operations (Suprem et al., 2013).

\subsection{Food processing industry}

In contrast to the automotive and aerospace industries, the food processing industry is still a slow adopter of RAS technologies even though they can increase the productivity of food processing in factories reducing costs and improving product quality (Suprem et al., 2013). Although RASs are applied in supply chains, the use of collaborative robots called cobots that can work side by side with human labour is untested. The integration of cobots can transform the food processing industry, where safe collaboration with human workers can increase the utilisation of high skilled workers and reduce risk to health within the industry. Some applications of RAS do not require direct contact with robots where the human workers only 
Duong et. al (preprint). A review of robotics and autonomous systems in the food industry: From the supply chains perspective. Trends in Food Science \& Technology. https://doi.org/10.1016/j.tifs.2020.10.028

monitor and remotely control the production lines, and typically RAS is important when tasks have hazards associated with them (Guiochet et al., 2017).

\subsection{RAS for livestock and aquaculture}

RAS is now regularly used for milking animals in dairies, and it is forecasted that RAS would be embedded in half of the dairy industry across the EU by 2025 (Beekman \& Bodde, 2015). The global milking robot market is expected to grow $10.3 \%$ yearly to reach the value of USD 3.127 Billion by the end of 2026 (Magnifier Research, 2020). RAS is also involved in other activities such as delivering food to livestock and removing waste. The traditional monitoring of the livestock by human workers can spread contamination and contribute to health hazards for operators, and RAS can perform these tasks regularly in previously a high-cost operation (von Borstel Luna et al., 2017).

Aquaculture is another opportunity for RAS because this type of environment has many challenges and difficulties. It is hostile to operators, and the work circumstances can be dangerous with substantial health and safety hazards as well as increased operating costs. Accordingly, the use of RAS could reduce the number of operators, improve the work conditions and ensure safety (von Borstel Luna et al., 2017).

\section{Methodology}

This paper follows a systematic literature review method; this identifies gaps in the literature and guides research to reliable knowledge (Tranfield et al., 2003). The method is suitable at investigating an extensive range of business and context to identify an in-depth understanding of the current literature. Specifically, this research followed a nine-step procedure (Figure 1), which has been used widely in recent literature review works (e.g., Duong \& Chong, 2020; Soosay \& Hyland, 2015). 
Duong et. al (preprint). A review of robotics and autonomous systems in the food industry: From the supply chains perspective. Trends in Food Science \& Technology. https://doi.org/10.1016/j.tifs.2020.10.028

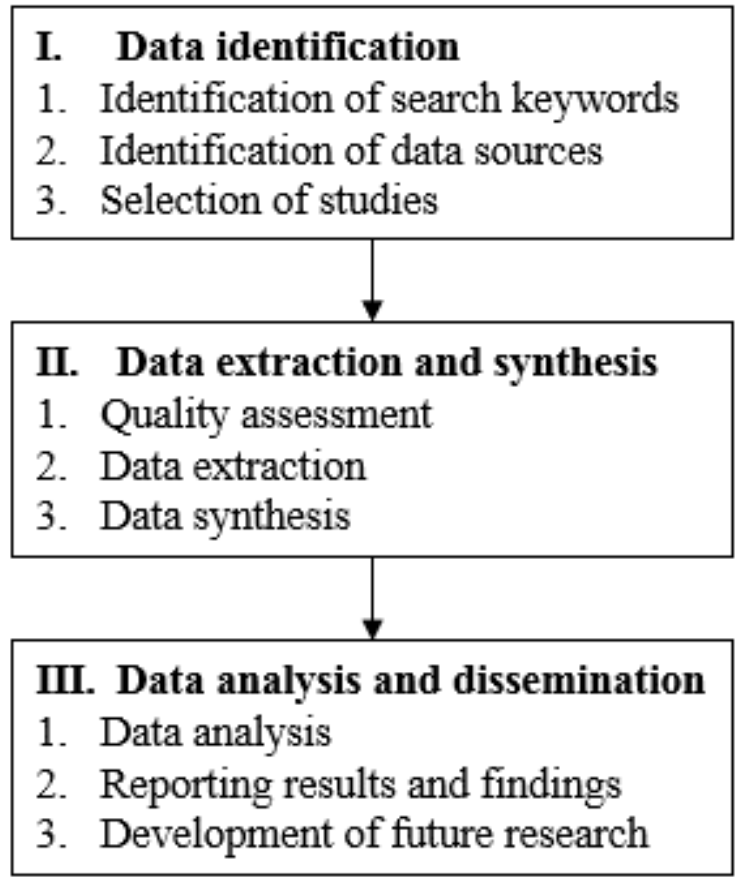

Figure 1. Systematic literature review procedure (Adapted from Tranfield et al. (2003))

\subsection{Data identification}

This process, including selecting data sources and relevant keywords, is iterative and necessary to investigate the literature (Tranfield et al., 2003). It has identified keywords and constructed search terms by examining recent literature review relating to the food supply chain (e.g., Kamble et al., 2020; Stone \& Rahimifard, 2018) and RAS (e.g., Olsen \& Tomlin, 2020; Rotz et al., 2019). The initial set of keywords (robot*, automate*, and autonomous) relates to RAS. The second set of keywords (food*, agri*, and farm*) are concerned with the food industry. The third set of keywords (supply, logistics, distribute*, warehouse*, sourcing*, procurement*, purchase*, production*, scheduling*, inventory*) are concerned with the supply chain management.

This study aligns with other recent literature review works; it has retrieved data from the Scopus and Web of Science libraries since the year 2000 to cover emerging works on the related field. Only papers written in English were selected with 2,532 and 2,004 papers extracted from Scopus and Web of Science libraries when duplicates were removed 3,106 remained.

\subsection{Data extraction and synthesis}

Screening data used the adopted PRISMA (Preferred Reporting Items for Systematic Reviews and Meta-Analysis) approach (Moher et al., 2015) (Figure 2). In line with Duong and Chong (2020), this research focused on high-quality journals that have an impact factor over one or 
Duong et. al (preprint). A review of robotics and autonomous systems in the food industry: From the supply chains perspective. Trends in Food Science \& Technology. https://doi.org/10.1016/j.tifs.2020.10.028

listed in the 2019 Australian Business Deans' Council (ABDC) or the ABS Academic Journal Guide 2018, 1325 papers were retained after this stage.

The title and abstract of each paper were inspected to evaluate whether it included the food supply chain perspective in the discussion of RAS. Furthermore, papers focusing on health, food, and engineering science areas such as 'biology', 'chemistry', 'medicine', and 'immunology' were excluded. This step resulted in 82 papers for full-text assessment. Of them, 28 papers were not relevant for the study as they discussed, for example, the application in an autonomous region or the impacts of dietary habits. The method produced a final list of 54 papers for data analysis and synthesis.
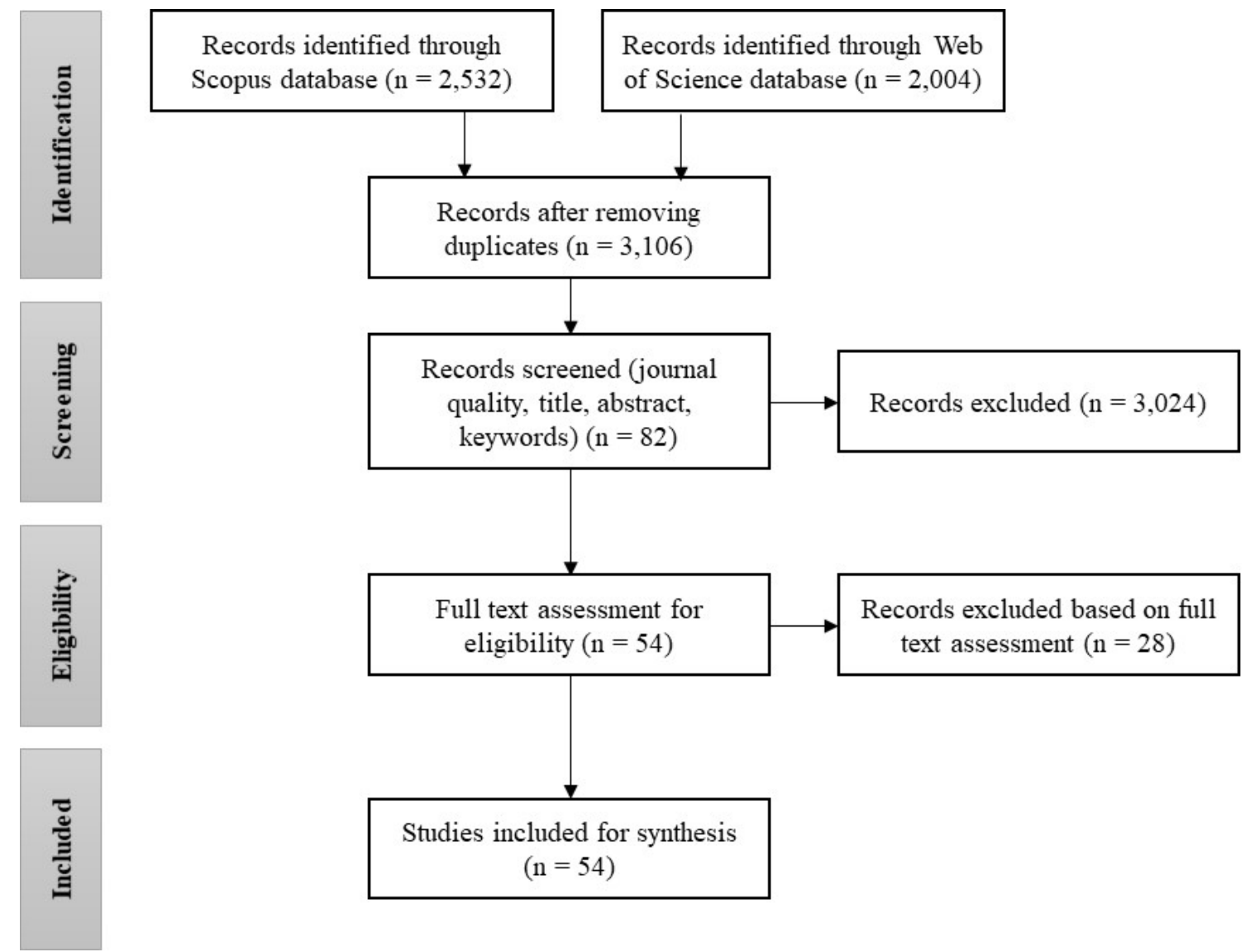

Figure 2. PRISMA flowchart for data screening.

\subsection{Data analysis and dissemination}

Two essential analyses were conducted in this research. The descriptive analysis offers an overview of selected papers, whereas the thematic analysis provides more comprehensive findings (Tan \& Taeihagh, 2020). All selected papers were imported into Nvivo 12, software 
Duong et. al (preprint). A review of robotics and autonomous systems in the food industry: From the supply chains perspective. Trends in Food Science \& Technology. https://doi.org/10.1016/j.tifs.2020.10.028

for analysing qualitative data (Jackson \& Bazeley, 2019), to enhance the quality of this review work.

Using the 'Word frequency' function, we identified the most important words in the selected papers (Table 1). These words have a strong connection with the search keywords and were validated so that analyses were conducted with high confidence.

Table 1. The most frequent keywords through text mining

\begin{tabular}{lrlrlr}
\hline Word & Frequency & Word & Frequency & Word & Frequency \\
\hline farm & 1,940 & informs & 717 & energy & 529 \\
products & 1,856 & operators & 716 & inventory & 522 \\
data & 1,754 & control & 707 & supplying & 520 \\
foods & 1,727 & plants & 668 & case & 519 \\
agriculture & 1,644 & impact & 662 & lands & 513 \\
adapt & 1,477 & industry & 660 & effects & 507 \\
changing & 1,351 & performs & 656 & measuring & 503 \\
technology & 1,338 & computing & 651 & water & 498 \\
robots & 1,284 & approach & 650 & sensors & 494 \\
process & 1,279 & methods & 625 & automations & 488 \\
crops & 1,201 & relation & 614 & rates & 483 \\
managing & 1,111 & order & 591 & implements & 483 \\
imaging & 1,025 & sustainability & 585 & environment & 477 \\
develops & 996 & optimizing & 571 & detects & 475 \\
climatic & 928 & applications & 564 & chains & 467 \\
areas & 824 & distributions & 563 & variables & 463 \\
value & 780 & designs & 558 & algorithms & 453 \\
researches & 769 & waste & 557 & economics & 449 \\
costs & 727 & cows & 555 & simulator & 442 \\
\hline
\end{tabular}

\subsection{Descriptive results}

This descriptive analysis section provides an overview of the selected papers. Figure 3 presents the publication year of the papers. It shows that there was an increase in the number of publications since 2013. The number of publications decreases in 2020 because the sample was collected in Feb 2020. 
Duong et. al (preprint). A review of robotics and autonomous systems in the food industry: From the supply chains perspective. Trends in Food Science \& Technology. https://doi.org/10.1016/j.tifs.2020.10.028

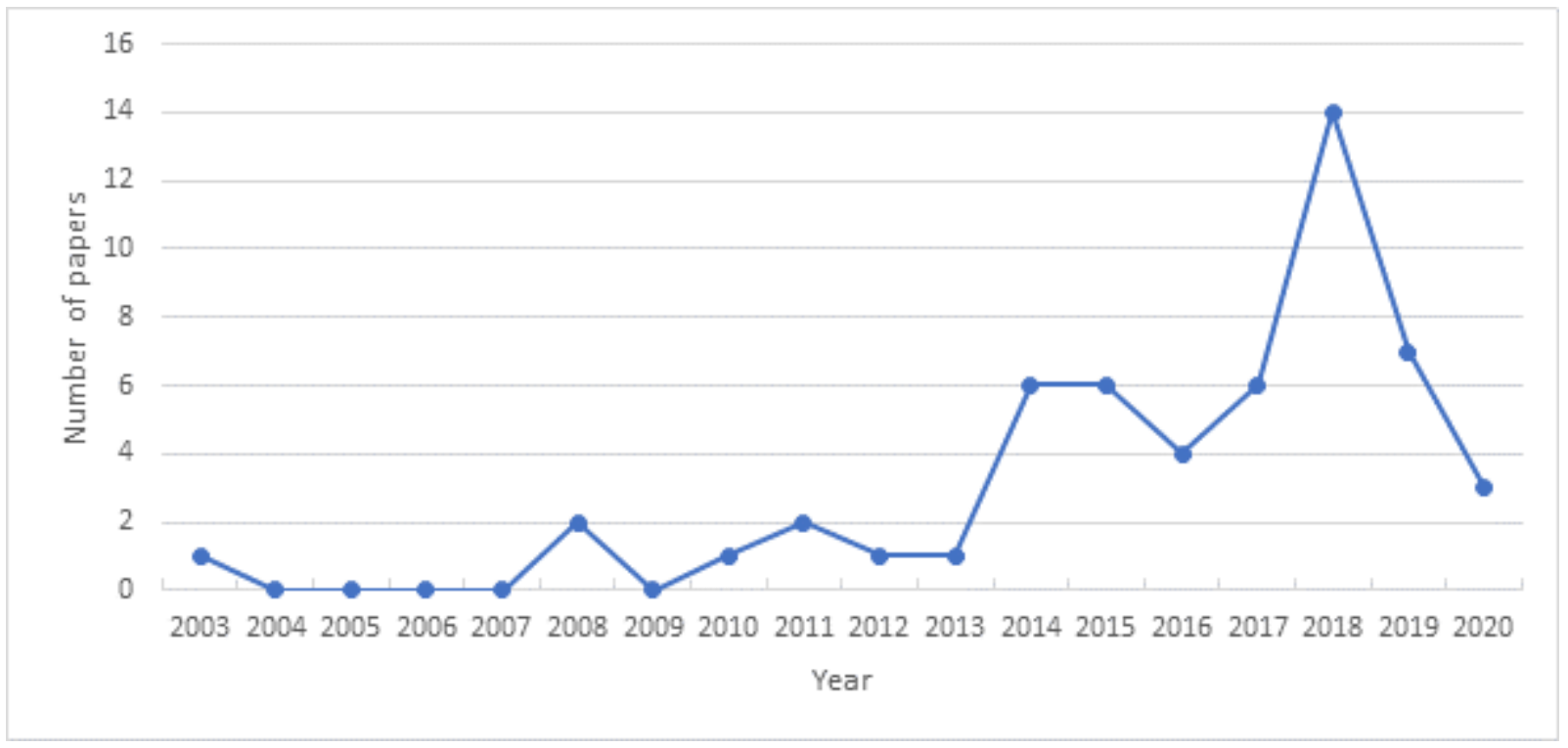

Figure 3. Total number of articles published by year

These papers were published in a total of 33 journals. Figure 4 presents the top eight journals which account for $54 \%$ of the sample. These journals are Sustainability; Plos One; Expert Systems with Applications; International Journal of Production Research; Computers in Industry; Journal of Cleaner Production; British Food Journal; and Climate and Development.

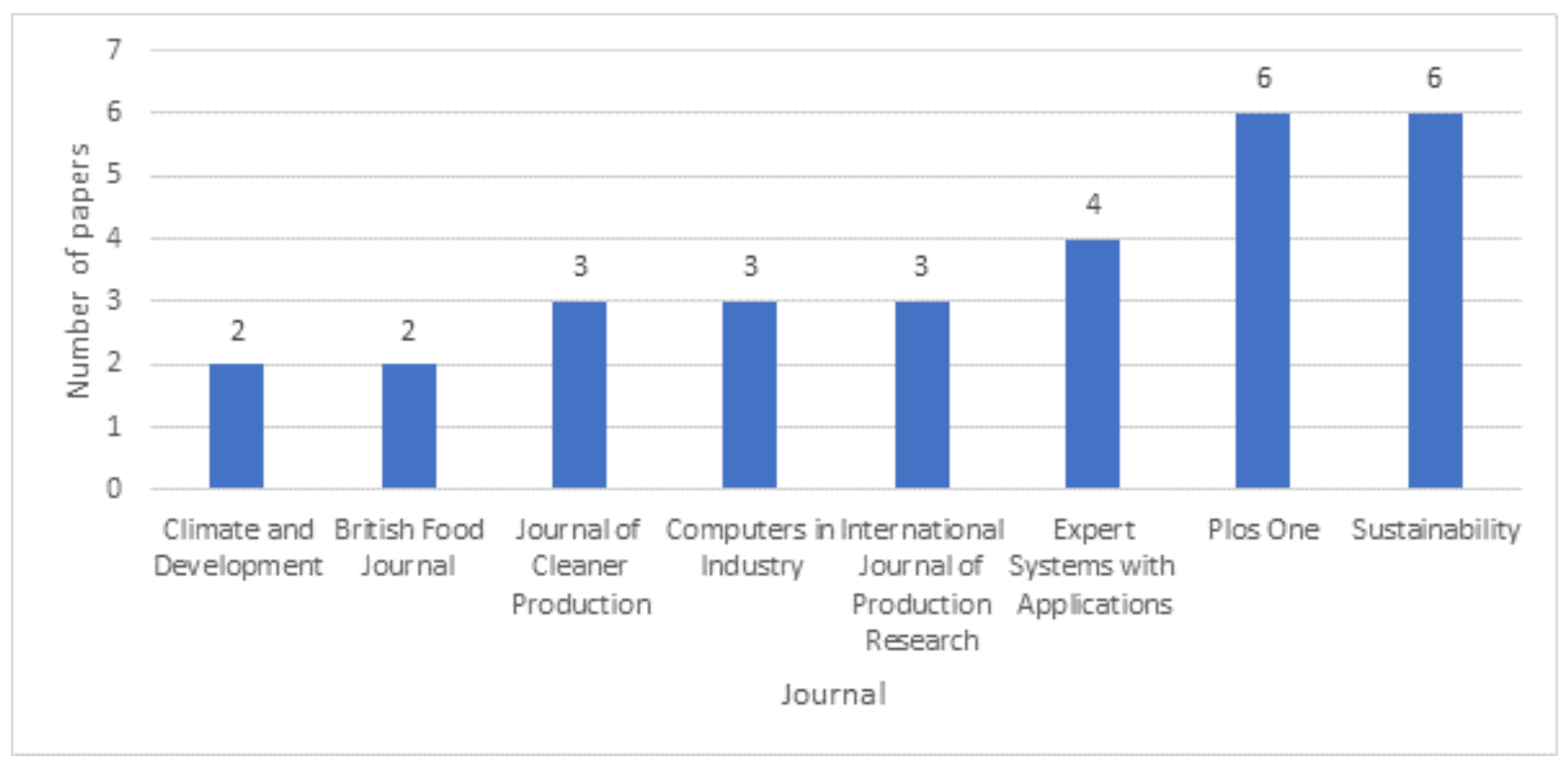

Figure 4. The most highly ranked eight journals that are most frequently published.

\section{Thematic analyses}

This section analyses the changes RAS bring to the food supply chains. The analysis considers major aspects, which were identified in recent works, including food quality, food safety, food 
Duong et. al (preprint). A review of robotics and autonomous systems in the food industry: From the supply chains perspective. Trends in Food Science \& Technology. https://doi.org/10.1016/j.tifs.2020.10.028

waste, supply chain efficiency, and supply chain analysis (Esteso et al., 2018; Zhong et al., 2017).

\subsection{Food quality}

The management of the food supply chain is complicated by specific process and product characteristics. One of the critical characteristics to consider is product quality which deteriorates depending on environmental conditions of transportation and storage facilities (Rong et al., 2011). The importance of food quality has been discussed widely after the occurrence of food recalls, for example, including high profile incidents of melamine contamination (Kong et al., 2019). Moreover, the movement of food products impacts sustainability because of the requirement of foods to have a specific range of temperature and humidity to maintain quality (van der Vorst et al., 2009). The majority of papers examining food quality at the farm, factory, or warehouse use computer vision or image processing methods (e.g., Rodgers, 2008; Trivelli et al., 2019). For example, fruit ripening is detected by flavour, colour, aroma, and texture to ensure fruit quality from the customer perspective. ElBendary et al. (2015) investigated tomato ripeness and delineated machine learning techniques to evaluate different stages of tomato ripeness automatically. Another study by Kurtulmuş and Kavdir (2014) investigated quality assurance of maise to ensure only hybrid seed is produced. The research developed a computer algorithm to detect the cutting locations of corn tassels for a more precise detasseling.

Following the complexity of managing temperature and humidity factors, the requirement of timely and accurate information throughout the food supply chain is a significant challenge for the food industry. Rapid technologies for automatic assessment and monitoring food quality are a must. In this context, image processing techniques, including edge detection, thresholding techniques, or texture, have been used widely. Tsakanikas et al. (2015) presented a methodology for automatic processing and information extraction from a multispectral image system. This work can be considered as an initial step towards automated and timely monitoring of food quality throughout the supply chain. It also enables efficient sampling of $100 \%$ of the food products in a timely manner and at a low cost. Some food chains, e.g., McDonald's and Sushi restaurants, installed complete robotic systems to take care of food preparation, food manufacturing, and food distribution to consumers (Khan et al., 2018). Recently, the concept of Cyber-Physical System (CPS), a research domain based on the concept of the Internet of Things, has received strong attention due to its potential to streamline the whole supply chain in the food sector (Iqbal et al., 2017). Haass et al. (2015), following the 
Duong et. al (preprint). A review of robotics and autonomous systems in the food industry: From the supply chains perspective. Trends in Food Science \& Technology. https://doi.org/10.1016/j.tifs.2020.10.028

idea of the Internet of Things, developed an algorithm which allowed containers containing bananas to make their own decisions with regards to the customer and the shipping route to be taken. The simulation results demonstrated the potential to reduce both carbon emission as well as the quality deterioration in bananas along the supply chain. These studies should be considered as a crucial step towards the adoption of RAS into the food supply chain. Future works might validate these findings on a larger scale or investigate the profitability of these systems.

\subsection{Food safety}

Generally, food safety refers to the avoidance of illness resulting from the consumption of contaminated food. The issue of food safety has been increasingly discussed through products recalls, for example, the presence of salmonella in chicken. Another well-known example of food safety crisis was the discovery of horsemeat in some beef products as well as the increased detection of porcine DNA in some processed "Halal" products in the United Kingdom (Fuseini et al., 2017). The growing attention towards food safety might be because of the increasingly stricter legislation and economic motivation (Akkerman et al., 2010). The food safety failure or recall can be a devastating factor and often tarnishes a company's reputation (Chen et al., 2018).

A wide range of standards and systems have been developed to help companies in order to manage food safety issues. For example, the Hazard Analysis Critical Control Point (HACCP) system aims to analyse and control biological, chemical, and physical hazards from the entire food supply chain (FDA, 2018). The core idea of HACCP is to offer a structured method to identify risks along the food supply chain and where possible either reduce those risks or eliminate them.

The underline of HACCP systems is the traceability of products along the food supply chain. Government has enforced legislation to actively encourage the traceability during all stages of production, manufacturing, and distribution. However, the complex and interconnected nature of food supply chains limits the ability to undertake traceability in the food industry. In this context, food companies have used RAS to address the traceability within their supply chains.

Kshetri (2018) described a recent success story where Walmart employed the RFID technology to enhance the safety of food on dinner tables of Chinese consumers. In this application, information such as details of farm origin, storage temperatures, processing data, expiration dates, and shipping details from an ecosystem of suppliers to store shelves and end consumers could reveal potential data on any food safety issues. Alternatively, Alfian et al. 
Duong et. al (preprint). A review of robotics and autonomous systems in the food industry: From the supply chains perspective. Trends in Food Science \& Technology. https://doi.org/10.1016/j.tifs.2020.10.028

(2017) utilised RFID and wireless sensor network to collect the temperature and humidity during storage and transportation of kimchi in South Korea. The proposed system helps by optimising the kimchi distribution, monitor freshness, and improves customer satisfaction level. However, the full benefits of RFID can only be achieved when all firms within the food chain implement the technology (Balocco et al., 2011). Full implementation of RFID technology across supply chain results in higher risk and costs for firms (Kelepouris et al., 2007). Due to the complexity of the food supply network and the fact that most food firms are small and medium, these requirements are significant barriers for adopting RFID in the food supply chain.

\subsection{Food waste}

As food production is resource-intensive, food waste has significant impacts on the environment such as water and air pollution, greenhouse gas emissions, and soil erosion that occur at all stages of food supply chains (Schanes et al., 2018). Along the food supply chain, nearly one-third of food products fit for human consumption is wasted or lost (Gustavsson et al., 2011). These environmental, social, and economic concerns highlight the importance of food waste issue, and unsurprisingly, there is an increasing amount of research undertaken using RAS.

Sensors and detection technologies have been used widely in order to monitor and thereby minimise food waste (Jagtap \& Rahimifard, 2019). Jagtap et al. (2019) proposed an automated and real-time system based on the Internet of Things to monitor the amount and the cause of potato waste within potato supply chains. The research demonstrates the use of modern image processing and load cell technologies which capture images of potatoes and measure the weight of each potato. Eriksson et al. (2019) aimed to quantify food waste in the hospitality sector using an internet-based service at 735 hotels, restaurants, and canteens in Europe, identifying factors that create food waste. In addition to direct replacement of labour, RAS can be used for extending labour's cognitive capacity. Noone and Coulter (2012) focused on the RAS application for demand prediction and production management for the quick-service restaurant. The proposed systems track consumer arrivals, cooking process, then gives directions to expedite cooking and customer service. Using the case of Zaxby's test outlets, the proposed systems substantially reduced food waste and service times. An obstacle to food waste reduction programmes is the lack of standards for quantifying and reporting food waste (Eriksson et al., 2019). Thus, there are few studies in our sample addressing the issue of food waste. This suggests that the use of RAS in food waste management is still an infancy research 
Duong et. al (preprint). A review of robotics and autonomous systems in the food industry: From the supply chains perspective. Trends in Food Science \& Technology. https://doi.org/10.1016/j.tifs.2020.10.028

area. It calls for a need to raise awareness about food waste by developing easy-to-implement quantifications.

\subsection{Supply chain efficiency}

Another research theme focuses on supply chain efficiency, which refers to a wide range of performance indicators such as overall costs, inventory level, and customer satisfaction (Lo et al., 2009). To measure these indicators, investment in information technologies among supply chain partners has become a strategic objective (Lee et al., 2011). It has been a rise in the usage of RFID and sensors to improve the efficiency of food supply chains. Ben-Daya et al. (2019) suggested using RFID and sensors to enable the adoption of Internet of Thing in the food supply chain. Integration of RFID and sensors for informed decision making is a critical activity in the food supply chain (Bouzembrak et al., 2019). For example, RFID could improve food safety monitoring, real-time tracking, or warehouse operations management, which increase sales volume and profitability (Mehrjerdi, 2010).

Other applications to increase supply chain efficiency include performing farming activities such as pruning, inspection, spraying (Tiotsop et al., 2020), automated dairy cattle body condition scoring system (Bewley et al., 2010), automated harvesting (Mann et al., 2016), automated refrigerated storage (Meneghetti \& Monti, 2015), or scheduling tasks in complex agriculture environment (Mazar et al., in press). The success of these applications depends on the communication between robots and the ability to analyse data (Sabzi \& Arribas, 2018). Gázquez et al. (2016) delved into the designation of intelligent telecontrol systems for agricultural machinery which offer solutions for robots and human working together in an agricultural environment whereas Schuetz et al. (2018) presented a data controlled warehouse to support business analytics in dairy farming.

\subsection{Supply chain analysis}

Supply chain analysis should be considered as a non-stop task rather than a one-time activity. In a fast-changing business environment, supply chain partners and relationships among them, internal and external factors of the supply chain keep evolving. Thus, supply chains need to accommodate in order to serve the consumers' requirements. For example, due to the fastchanging attributes of food products, Duong et al. (2018) proposed using non-financial measures to manage the inventory of such products. Results from the initial analysis could be used as a starting point or for benchmarking. These analyses reflect the continuous changes in the business environment. In this way, RAS could provide accurate and timely information for supply chain analysis and in return, support the implementation of the analysis results. 
Duong et. al (preprint). A review of robotics and autonomous systems in the food industry: From the supply chains perspective. Trends in Food Science \& Technology. https://doi.org/10.1016/j.tifs.2020.10.028

A typical example within this category is the use of robots and drones in the food industry (Dahabieh et al., 2018). The robot works as a delivery person, receiving finished food products from a restaurant kitchen and passing it to the intended consumers, whilst drones have been used at farms to monitor the production processes and parameters. These technologies are still in the early stages but have demonstrated some promising and noticeable results. Another example is the use of 3D food printing technologies which provide a solution for new food product development and could reconfigure the whole food supply chain (Sun et al., 2015). Alternatively, Kaur and Kaur (2018) proposed a cloud-based IoT-enabled grocery management system for the organisation of four automated units: manufacturers, warehouses, stores, and consumers. The proposed system aids the communication between these four units and makes grocery procurement easier for the consumers.

Another example in this category relates to the applications that offer better reuse of natural resources. Rodias et al. (2017) delved into automated navigation systems that reduced the energy requirements in agriculture. Gružauskas et al. (2018) presented a way of using autonomous vehicles to minimise the trade-off between environmental effects and costeffective performance. The obtained results showed that the proposed autonomous vehicle strategy decreased $22 \% \mathrm{CO}_{2}$ level. Nadal et al. (2017) developed an automated methodology with airborne sensors for identifying the feasibility of implementing rooftop greenhouses in urban areas. These applications require not only enough data from the business environment around but also the abilities for data analysis. Thus, it calls for effective usage of available data, and big data analysis is an option.

\section{Discussion}

This paper conducted a literature review on the application of RAS in the food industry from the supply chain management perspective. Using a nine-step procedure, this paper collected a sample of 54 relevant articles from Scopus and Web of Science for analysis. These articles were coded in Nvivo and categorised into five groups of applications: food safety, food quality, food waste, supply chain efficiency, and supply chain analysis. Findings from this review suggest that RAS resulted in significant changes within the food supply chain. Drones can help farmers inspect crops, livestock and farm machinery at speed and at a scale that has never been seen before. RAS is expected to change the operation of the farm. It can also change the influence of each supply chain partners and the relationship between them. We discuss these findings in detail as follows. 
Duong et. al (preprint). A review of robotics and autonomous systems in the food industry: From the supply chains perspective. Trends in Food Science \& Technology. https://doi.org/10.1016/j.tifs.2020.10.028

\subsection{The role of RAS in the food supply chain}

Contemporary issues such as sustainability, food safety, and food security require the application of RAS to go beyond the farm and cover the entire supply chain. An effort to increase the efficiency at a farm will not necessarily benefit consumers due to a poor distribution network. However, the majority of our sample papers focuses on the RAS applications at the farm. This reflects constraints due to the nature and the structure of the food industry (Matopoulos et al., 2007). A typical food supply chain might include a huge number of partners such as farmers, suppliers, pack-houses, importers, exporters, retailers, and consumers. This complex structure results in numerous interactions. The more the number of partners in the food supply chain, the more the shared information between these partners. Additionally, across the globe, most firms in food supply chains are categorised as small and medium enterprises with limited finance and resources (Vandeplas et al., 2013). These complexities hinder collaborative efforts to adopt RAS within the food supply chain. Moreover, these systems require information infrastructure to operate and maintain. This might be a technical barrier and prevent the access of food companies.

Further, the application of RAS in food supply chains is still at an early stage. This conclusion is based on the limited number of collected papers in the sample. It is in line with findings suggested from studies on Big Data in farming (Jagtap \& Duong, 2019; Wolfert et al., 2017) and Industry 4.0 (Trivelli et al., 2019). These studies highlighted the limited number of applications of Big Data or Industry 4.0 in the food industry; this may be due to the financial and manpower constraints (Trivelli et al., 2019). Similarly, while conducting a review of applications on blockchain technology, Zhao et al. (2019) found that the implementation of blockchain in food supply chains is still in the testing phase. A reason for the lack of RAS applications in the food industry is that this industry requires high standards for safety and hygiene processes (Khan et al., 2018). Moreover, issues such as the food raw materials or products variation in shapes and sizes challenge the measuring methods for food ingredients and recipe. While RAS is a promising technology, many attempts to substitute humans with robots for these kinds of activities have been unsuccessful, e.g., due to the availability of certified repairperson and the high costs. Thus, future research can shed light on the barriers to the application of RAS in the food supply chain.

\subsection{The availability of data}

To provide proven benefits, it is necessary to have each partner in the food supply chain to implement RAS applications. These partners will generate a huge amount of information, i.e., 
Duong et. al (preprint). A review of robotics and autonomous systems in the food industry: From the supply chains perspective. Trends in Food Science \& Technology. https://doi.org/10.1016/j.tifs.2020.10.028

Big Data (Terazono, 2018). This Big Data provides opportunities to access, analyse, and make better decisions at each stage of the supply chain or for the entire supply chain (Wolfert et al., 2017). For example, many rice farmers in Taiwan rely on the traditional farming calendar, but climate change has affected that calendar significantly. Thus, rice farmers in Taiwan with a set of sensors are monitoring temperature, rain, and chemicals to optimise the rice production cycle (Hille, 2018). As the number of partners, transactions, and factors (e.g., environment, chemicals) increases, the amount of data becomes bigger, which requires additional resources (e.g., data storage capacity). It also provides opportunities for future studies on the applications of big data analytics in the food supply chain.

\subsection{Cybersecurity}

Food manufacturers are reluctant to embrace the RAS systems as they generate a huge amount of data which raises the concern about data security and privacy. Innovations in the food industry are driven by data. Analysis of data about products, production process, or the movement of the products along the supply chain can ensure the sustainability of the business and provide advice to involved stakeholders. Unfortunately, when data is the key driver, its vulnerability is a critical threat to the industry. The biggest concern is that industry trade secrets or recipes might get leaked to the competitors resulting in loss of business or market share. The other important reason is that when the data becomes transparent, there is a threat to profit margin; for instance, retailers will squeeze manufacturers to produce food products at lower costs (Jagtap \& Rahimifard, 2019). Also, in 2019, a ransomware attack on Norsk Hydro, a global aluminium company, cost them $£ 45$ million and infected 22,000 computers across 170 different sites in 40 different countries (Tidy, 2019). Such incidents can affect food manufacturers as well as their supply chain. Hackers could easily find their way into a company's information technology system and bring a company to its knees through turning off hardware, rerouting of logistics and cancelling orders - in return of a huge sum of monies. A report published by Ponemon Institute in 2011 stated that 50 US-based companies affected by malware attacks represented for $40 \%$ of their overall losses (Ponemon Institute, 2011). Researchers at Georgia Institute of Technology successfully demonstrated how by using ransomware, they could manipulate a system to dump a huge amount of chlorine into water (Biggs, 2017). In order to protect the system from outsiders, Gázquez et al. (2016) developed a special-purpose UHF narrowband modem for communication between the console to the vehicle. There is an increasing number of efforts to tackle the security and privacy issues; however, it remains as one of the key challenges (Wolfert et al., 2017). Future research can 
Duong et. al (preprint). A review of robotics and autonomous systems in the food industry: From the supply chains perspective. Trends in Food Science \& Technology. https://doi.org/10.1016/j.tifs.2020.10.028

investigate how to build trust among supply chain partners, which can also accelerate RAS adoption. Alternatively, many start-ups or small and medium enterprises have paid attention to the development of RAS in the food industry (Hahn, 2020). These companies are mostly local and have strong knowledge of the food industry in their geographical locations. Thus, it is beneficial to explore RAS solutions which could help such companies as they are quite open, flexible and quick to implement these solutions.

\subsection{Skill capability}

The food industry is characterised as a labour-intensive industry and normally faces a seasonal labour shortage. Demand for labour is highest during times for land preparation, sowing, and harvesting. As much of this industry relies heavily on migrant labour, any change on policy causes significant effects on labour availability. For example, food factory vacancies in the United Kingdom are becoming tougher to fill as many European Union workers are leaving the country due to the falling rate of Sterling pound, uncertainty around freedom of movement, and their future status since the Brexit referendum (Hope, 2019). Alternatively, Trump administration's plan for increased deportations and a wall on the United State-Mexico border would have a profound impact on American agriculture (Martin, 2017). Recently, the current Covid-19 pandemic has further exposed the criticality of food manufacturers (Sarkis et al., 2020). It is getting more difficult to recruit seasonal workers due to travel restrictions around the world and a reduction in the availability of public transport services. Many factories have to close or run at a slower speed as managing two-metre distance rule would be a challenge. Besides these events, the growing rate of urbanisation, the shift in the residence of the human population from rural to urban areas, is the other critical one. The United Nations projections showed that the world's population lives in urban areas may increase to $68 \%$ by 2050 (United Nations, 2018). Subsequently, the rural population would decline and worsen the labour shortage issues in the food industry.

These labour shortage issues motivate companies to adopt RAS into their businesses while there is fear among factory workers and governments that RAS will take away the majority of jobs, as well as there is a lack of skills in the market to cater RAS needs. To outline some key trends for farm labour, Rotz et al. (2019) conducted a literature review followed with interviews from scholars and farmers in Canada. The authors found that the current low levels of education and skills discourage farmers from adopting emerging technologies while a considerable number of farmers are willing to shift employment strategy by hiring more highly skilled labour. However, farmers are also concerned about government policies and programmes for 
Duong et. al (preprint). A review of robotics and autonomous systems in the food industry: From the supply chains perspective. Trends in Food Science \& Technology. https://doi.org/10.1016/j.tifs.2020.10.028

upskilling labour. A possible solution could be the co-operation between educational institutes and commercial organisations. This co-operation can be complex as institutes have different objectives such as knowledge dissemination, whilst companies are interested in owning Intellectual Property rights. Surprisingly, we do not find any paper in our sample that offers a clear solution for this challenge. Therefore, it provides a promising future research direction in this area.

\subsection{Financial cost}

RAS systems offer solutions for increasing efficiency in the food supply chains, but they can be cost-prohibitive. The high cost of these systems is a constraint for the adoption (Ortiz et al., 2018). In our sample, most of RAS applications are based on the use of sensors. Although the price of sensors has declined recently, they are still considered more qualitative than quantitative. In general, these low-cost sensors provide a simple measurement. They reduce repeatability and accuracy and thus require suitable calibrations for increased efficiency (Ortiz et al., 2018). Gázquez et al. (2016) proposed the use of low-cost telescope system for agricultural vehicles. Such development could be scaled up to benefit a wider community. It is noted that the objective of RAS systems is not to exceed the final cost of food products but to keep the cost of these systems as low as possible so not to increase the final cost for the end consumers leading to changes in the consumer behaviour (Bibi et al., 2017).

\section{Conclusion and future research directions}

RAS is being developed rapidly and thought to be a promising technology. The adoption of RAS in the food supply chain improves the management as well as increase the quality and efficiency. Robots have huge potential and are advantageous to the food industry, but engineers and industry practitioners must progress with care to guarantee food safety. Food robots must be equipped with suitable sensor systems so that they pose no risk to anyone in contact with them. With the rising labour cost and labour shortage due to uncertain political policies and disruption events, RAS might be one of the approaches to make food affordable. Simple, easy and reliable approaches must be adopted to fine-tune a robot so that ideal performance can be accomplished without any problem. Although several areas of the food manufacturing sector will benefit from robotic devices; the robotic devices specifically designed for food production will help reduce the time and cost of production. They could make a great contribution to the food manufacturing sector in a brief timeframe and hence are currently being pursued widely.

According to our review, food safety, food quality, food waste, supply chain efficiency, and supply chain analysis benefit from the adoption of RAS in the food supply chains. However, 
Duong et. al (preprint). A review of robotics and autonomous systems in the food industry: From the supply chains perspective. Trends in Food Science \& Technology. https://doi.org/10.1016/j.tifs.2020.10.028

the lack of RAS applications, the availability of data, cybersecurity, skill capability, and high costs are challenges for RAS adoption. Results from this research highlight some research gaps as listed below.

- What are the barriers to the adoption of RAS in the food supply chains? For example, how to build and maintain the trust among partners in the food supply chains for the RAS adoption?

- What are successful collaborative mechanisms to implement a RAS application? While we note that collaboration is important in RAS adoption, the current literature does not offer clear collaboration mechanisms. Should the technology companies or the manufacturer or the farmer lead the collaboration?

- What are opportunities to combine RAS and other emerging technologies such as blockchain or big data? For example, how to explore the interplay between RAS and "things" or the development of IoT-aided RAS applications (Grieco et al., 2014) in the food industry. How to enhance data storage capacity in the food industry?

- How to protect the privacy of food supply chain partners? How to share knowledge among food supply chain partners? For example, some applications aim to reduce carbon emission and energy consumption at food manufacturers, but it is unclear how to protect consumer information or production recipes at these manufacturers.

- What programmes are required to increase labour skills in the food industry? For example, what are the collaborative mechanisms among farmers, universities, and government agencies for building labour skills?

- As for the high-cost issue, what are the trade-offs between the level of investment and benefits for the food supply chain partners? What could incentive schemes government offer to increase the RAS adoption? As it is essential to demonstrate to firms the benefits and return on such investments (Li \& Wang, 2017).

- Majority RAS applications within our samples are based on the use of sensors or computer vision. They are part of a broader theme: Digitalisation (Bibi et al., 2017). While we might expect to observe papers exploring the involvement of robots for autonomous responses, this is not a surprising fact as we search for papers from the supply chain management perspective highlighting the management of the flow of goods and services between the supply chain partners. Future research could relax or modify search criteria in this paper to investigate the adoption of RAS from different perspectives or, broadly, the digitalisation in the food supply chains. 
Duong et. al (preprint). A review of robotics and autonomous systems in the food industry: From the supply chains perspective. Trends in Food Science \& Technology. https://doi.org/10.1016/j.tifs.2020.10.028

- Finally, the findings in this research suggest that there might be a gap between academic and industry practitioners on RAS adoption. While business reports from Financial Times or McKinsey highlight the role of RAS in the food supply chain (e.g. Djanian \& Ferreira, 2020; McGee, 2020), there is not a significant number of academic papers in this topic. Is it because researchers focus on broader themes such as blockchain or big data? Thus, we need to engage more academic-practitioner collaborative studies to bridge this gap (Bartunek, 2016).

\section{Acknowledgement}

The authors thank Professor Rickey Yada and anonymous reviewers for valuable comments that significantly improved the manuscript.

\section{References}

Akkerman, R., Farahani, P., \& Grunow, M. (2010). Quality, safety and sustainability in food distribution: A review of quantitative operations management approaches and challenges. OR Spectrum, 32(4), 863-904. https://doi.org/10.1007/s00291-010-0223-2

Alfian, G., Rhee, J., Ahn, H., Lee, J., Farooq, U., Ijaz, M. F., \& Syaekhoni, M. A. (2017). Integration of RFID, wireless sensor networks, and data mining in an e-pedigree food traceability system. Journal of Food Engineering, 212(1), 65-75. https://doi.org/10.1016/j.jfoodeng.2017.05.008

Balocco, R., Miragliotta, G., Perego, A., \& Tumino, A. (2011). RFID adoption in the FMCG supply chain: An interpretative framework. Supply Chain Management: An International Journal, 16(5), 299-315. https://doi.org/10.1108/13598541111155820

Bartunek, J. M. (2016). A more relevant approach to relevance in management studies: An essay on performativity. Academy of Management Review, 41(2), 367-381. https://doi.org/10.5465/amr.2015.0205 
Duong et. al (preprint). A review of robotics and autonomous systems in the food industry: From the supply chains perspective. Trends in Food Science \& Technology. https://doi.org/10.1016/j.tifs.2020.10.028

Beekman, J., \& Bodde, R. (2015). Milking automation is gaining popularity. Dairy Global. https://www.dairyglobal.net/Milking/Articles/2015/1/Milking-automation-is-gainingpopularity-1568767W/

Ben-Daya, M., Hassini, E., \& Bahroun, Z. (2019). Internet of things and supply chain management: A literature review. International Journal of Production Research, 57(15-16), 4719-4742. https://doi.org/10.1080/00207543.2017.1402140

Bewley, J. M., Boehlje, M. D., Gray, A. W., Hogeveen, H., Kenyon, S. J., Eicher, S. D., \& Schutz, M. M. (2010). Assessing the potential value for an automated dairy cattle body condition scoring system through stochastic simulation. Agricultural Finance Review, 70(1), 126-150. https://doi.org/10.1108/00021461011042675

Bibi, F., Guillaume, C., Gontard, N., \& Sorli, B. (2017). A review: RFID technology having sensing aptitudes for food industry and their contribution to tracking and monitoring of food products. Trends in Food Science \& Technology, 62, 91-103. https://doi.org/10.1016/j.tifs.2017.01.013

Biggs, J. (2017). Researchers simulate a ransomware attack on industrial controls. TechCrunch. $\quad$ https://social.techcrunch.com/2017/02/13/researchers-simulate-aransomware-attack-on-industrial-controls/

Bloch, V., Degani, A., \& Bechar, A. (2018). A methodology of orchard architecture design for an optimal harvesting robot. Biosystems Engineering, 166, 126-137. https://doi.org/10.1016/j.biosystemseng.2017.11.006

Bogue, R. (2020). Fruit picking robots: Has their time come? Industrial Robot, 47(2), 141-145. https://doi.org/10.1108/ir-11-2019-0243

Bouzembrak, Y., Klüche, M., Gavai, A., \& Marvin, H. J. P. (2019). Internet of Things in food safety: Literature review and a bibliometric analysis. Trends in Food Science \& Technology, 94, 54-64. https://doi.org/10.1016/j.tifs.2019.11.002 
Duong et. al (preprint). A review of robotics and autonomous systems in the food industry: From the supply chains perspective. Trends in Food Science \& Technology. https://doi.org/10.1016/j.tifs.2020.10.028

Cai, S., Ma, Z., Skibniewski, M. J., \& Bao, S. (2019). Construction automation and robotics for high-rise buildings over the past decades: A comprehensive review. Advanced Engineering Informatics, 42, 100989. https://doi.org/10.1016/j.aei.2019.100989

Chen, Y., Huang, S., Mishra, A. K., \& Wang, X. H. (2018). Effects of input capacity constraints on food quality and regulation mechanism design for food safety management. Ecological Modelling, 385, 89-95. https://doi.org/10.1016/j.ecolmodel.2018.03.011

Dahabieh, M. S., Bröring, S., \& Maine, E. (2018). Overcoming barriers to innovation in food and agricultural biotechnology. Trends in Food Science \& Technology, 79, 204-213. https://doi.org/10.1016/j.tifs.2018.07.004

Djanian, M., \& Ferreira, N. (2020). Agriculture trends disrupting the food value chain. McKinsey. https://www.mckinsey.com/industries/agriculture/our-insights/agriculturesector-preparing-for-disruption-in-the-food-value-chain

Driessen, C., \& Heutinck, L. F. M. (2015). Cows desiring to be milked? Milking robots and the co-evolution of ethics and technology on Dutch dairy farms. Agriculture and Human Values, 32(1), 3-20. https://doi.org/10.1007/s10460-014-9515-5

Duong, L. N. K., \& Chong, J. (2020). Supply chain collaboration in the presence of disruptions: A literature review. International Journal of Production Research, 58(11), 3488-3507. https://doi.org/10.1080/00207543.2020.1712491

Duong, L. N. K., Wood, L. C., \& Wang, W. Y. C. (2018). Effects of consumer demand, product lifetime, and substitution ratio on perishable inventory management. Sustainability, 10(5), 1-17. https://doi.org/10.3390/su10051559

El-Bendary, N., El Hariri, E., Hassanien, A. E., \& Badr, A. (2015). Using machine learning techniques for evaluating tomato ripeness. Expert Systems with Applications, 42(4), 1892-1905. https://doi.org/10.1016/j.eswa.2014.09.057 
Duong et. al (preprint). A review of robotics and autonomous systems in the food industry: From the supply chains perspective. Trends in Food Science \& Technology. https://doi.org/10.1016/j.tifs.2020.10.028

Elferink, M., \& Schierhorn, F. (2016, April 7). Global demand for food is rising. Can we meet it? Harvard Business Review, 94(4), 2-5.

Eriksson, M., Malefors, C., Callewaert, P., Hartikainen, H., Pietiläinen, O., \& Strid, I. (2019). What gets measured gets managed - Or does it? Connection between food waste quantification and food waste reduction in the hospitality sector. Resources, Conservation \& Recycling: X, 4, 100021. https://doi.org/10.1016/j.rcrx.2019.100021

Esteso, A., Alemany, M. M. E., \& Ortiz, A. (2018). Conceptual framework for designing agrifood supply chains under uncertainty by mathematical programming models. International Journal of Production Research, 56(13), 4418-4446. https://doi.org/10.1080/00207543.2018.1447706

FDA. (2018). Hazard analysis critical control point (HACCP). FDA; FDA. https://www.fda.gov/food/guidance-regulation-food-and-dietary-supplements/hazardanalysis-critical-control-point-haccp

Fentanes, J. P., Badiee, A., Duckett, T., Evans, J., Pearson, S., \& Cielniak, G. (2020). Krigingbased robotic exploration for soil moisture mapping using a cosmic-ray sensor. Journal of Field Robotics, 37(1), 122-136. https://doi.org/10.1002/rob.21914

Fuseini, A., Wotton, S. B., Knowles, T. G., \& Hadley, P. J. (2017). Halal meat fraud and safety issues in the UK: A review in the context of the European Union. Food Ethics, 1(2), 127-142. https://doi.org/10.1007/s41055-017-0009-1

Gázquez, J. A., Castellano, N. N., \& Manzano-Agugliaro, F. (2016). Intelligent low cost telecontrol system for agricultural vehicles in harmful environments. Journal of Cleaner Production, 113, 204-215. https://doi.org/10.1016/j.jclepro.2015.11.015

Grieco, L. A., Rizzo, A., Colucci, S., Sicari, S., Piro, G., Di Paola, D., \& Boggia, G. (2014). IoT-aided robotics applications: Technological implications, target domains and open 
Duong et. al (preprint). A review of robotics and autonomous systems in the food industry: From the supply chains perspective. Trends in Food Science \& Technology. https://doi.org/10.1016/j.tifs.2020.10.028

issues. Computer $\quad$ Communications, $\quad 34,47$. https://doi.org/10.1016/j.comcom.2014.07.013

Grimm, J. H., Hofstetter, J. S., \& Sarkis, J. (2014). Critical factors for sub-supplier management: A sustainable food supply chains perspective. International Journal of Production Economics, 152(1), 159-173. https://doi.org/10.1016/j.ijpe.2013.12.011

Gružauskas, V., Baskutis, S., \& Navickas, V. (2018). Minimising the trade-off between sustainability and cost effective performance by using autonomous vehicles. Journal of Cleaner Production, 184, 709-717. https://doi.org/10.1016/j.jclepro.2018.02.302

Guiochet, J., Machin, M., \& Waeselynck, H. (2017). Safety-critical advanced robots: A survey. Robotics and Autonomous Systems, 94, 43-52. https://doi.org/10.1016/j.robot.2017.04.004

Gustavsson, J., Cederberg, C., Sonesson, U., Van Otterdijk, R., \& Meybeck, A. (2011). Global food losses and food waste: Extent, causes and prevention. www.fao.org/docrep/014/mb060e/mb060e.pdf

Haass, R., Dittmer, P., Veigt, M., \& Lütjen, M. (2015). Reducing food losses and carbon emission by using autonomous control - A simulation study of the intelligent container. International Journal of Production Economics, 164, 400-408. https://doi.org/10.1016/j.ijpe.2014.12.013

Hahn, G. J. (2020). Industry 4.0: A supply chain innovation perspective. International Journal of Production Research, 58(5), 1425-1441. https://doi.org/10.1080/00207543.2019.1641642

Hille, K. (2018, December 10). Taiwan's rice farmers use big data to cope with climate change. Financial Times. https://www.ft.com/content/9f5438fa-ee2d-11e8-89c8$\mathrm{d} 36339 \mathrm{~d} 835 \mathrm{c} 0$ 
Duong et. al (preprint). A review of robotics and autonomous systems in the food industry: From the supply chains perspective. Trends in Food Science \& Technology. https://doi.org/10.1016/j.tifs.2020.10.028

Hope, M. (2019, October 17). The economic impact of Brexit on London. London City Hall. https://www.london.gov.uk//business-and-economy-publications/economic-impactbrexit-london

Iqbal, J., Khan, Z. H., \& Khalid, A. (2017). Prospects of robotics in food industry. Food Science and Technology, 37(2), 159-165. https://doi.org/10.1590/1678-457x.14616

Ivanov, S., Gretzel, U., Berezina, K., Sigala, M., \& Webster, C. (2019). Progress on robotics in hospitality and tourism: A review of the literature. Journal of Hospitality and Tourism Technology, 10(4), 489-521. https://doi.org/10.1108/jhtt-08-2018-0087

Jackson, K., \& Bazeley, P. (2019). Qualitative data analysis with NVivo. SAGE.

Jagtap, S., Bhatt, C., Thik, J., \& Rahimifard, S. (2019). Monitoring potato waste in food manufacturing using image processing and internet of things approach. Sustainability, 11(11), 3173. https://doi.org/10.3390/su11113173

Jagtap, S., \& Duong, L. N. K. (2019). Improving the new product development using big data: A case study of a food company. British Food Journal, 121(11), 2835-2848. https://doi.org/10.1108/bfj-02-2019-0097

Jagtap, S., \& Rahimifard, S. (2019). The digitisation of food manufacturing to reduce waste Case study of a ready meal factory. Waste Management, 87, 387-397. https://doi.org/10.1016/j.wasman.2019.02.017

Kamble, S. S., Gunasekaran, A., \& Gawankar, S. A. (2020). Achieving sustainable performance in a data-driven agriculture supply chain: A review for research and applications. International Journal of Production Economics, 219(1), 179-194. https://doi.org/10.1016/j.ijpe.2019.05.022

Kaur, J., \& Kaur, P. D. (2018). CE-GMS: A cloud IoT-enabled grocery management system. Electronic Commerce Research and Applications, 28, 63-72. https://doi.org/10.1016/j.elerap.2018.01.005 
Duong et. al (preprint). A review of robotics and autonomous systems in the food industry: From the supply chains perspective. Trends in Food Science \& Technology. https://doi.org/10.1016/j.tifs.2020.10.028

Kavadias, S., \& Ulrich, K. T. (2020). Innovation and new product development: Reflections and insights from the research published in the first 20 years of manufacturing $\&$ service operations management. Manufacturing \& Service Operations Management, 22(1), 84-92. https://doi.org/10.1287/msom.2019.0816

Kelepouris, T., Pramatari, K., \& Doukidis, G. (2007). RFID-enabled traceability in the food supply chain. Industrial Management \& Data Systems, 107(2), 183-200. https://doi.org/10.1108/02635570710723804

Khan, Z. H., Khalid, A., \& Iqbal, J. (2018). Towards realising robotic potential in future intelligent food manufacturing systems. Innovative Food Science \& Emerging Technologies, 48, 11-24. https://doi.org/10.1016/j.ifset.2018.05.011

Kong, D., Shi, L., \& Yang, Z. (2019). Product recalls, corporate social responsibility, and firm value: Evidence from the Chinese food industry. Food Policy, 83(1), 60-69. https://doi.org/10.1016/j.foodpol.2018.11.005

Kshetri, N. (2018). 1 Blockchain's roles in meeting key supply chain management objectives. International Journal of Information Management, 39, 80-89. https://doi.org/10.1016/j.ijinfomgt.2017.12.005

Kurtulmuş, F., \& Kavdir, İ. (2014). Detecting corn tassels using computer vision and support vector machines. Expert Systems with Applications, 41(16), 7390-7397. https://doi.org/10.1016/j.eswa.2014.06.013

Lee, J., Palekar, U. S., \& Qualls, W. (2011). Supply chain efficiency and security: Coordination for collaborative investment in technology. European Journal of Operational Research, 210(3), 568-578. https://doi.org/10.1016/j.ejor.2010.10.015

Lezoche, M., Hernandez, J. E., Alemany Díaz, M. D. M., Panetto, H., \& Kacprzyk, J. (2020). Agri-food 4.0: A survey of the supply chains and technologies for the future agriculture. 
Duong et. al (preprint). A review of robotics and autonomous systems in the food industry: From the supply chains perspective. Trends in Food Science \& Technology. https://doi.org/10.1016/j.tifs.2020.10.028

$\begin{array}{llll}\text { Computers } \quad \text { in } \quad \text { Industry, } & 117(1), & \end{array}$

https://doi.org/10.1016/j.compind.2020.103187

Li, D., \& Wang, X. (2017). Dynamic supply chain decisions based on networked sensor data: An application in the chilled food retail chain. International Journal of Production Research, 55(17), 5127-5141. https://doi.org/10.1080/00207543.2015.1047976

Lo, C. K. Y., Yeung, A. C. L., \& Cheng, T. C. E. (2009). ISO 9000 and supply chain efficiency: Empirical evidence on inventory and account receivable days. International Journal of Production Economics, 118(2), 367-374. https://doi.org/10.1016/j.ijpe.2008.11.010

Magnifier Research,. (2020). Global robotics milking systems market 2020 with (Covid-19) impact analysis, product type, application, key manufacturers, regions and forecast to 2025. Magnifier Research. https://www.magnifierresearch.com/report/global-roboticsmilking-systems-market-report-2020-forecast-33211.html

Mann, M., Zion, B., Shmulevich, I., \& Rubinstein, D. (2016). Determination of robotic melon harvesting efficiency: A probabilistic approach. International Journal of Production Research, 54(11), 3216-3228. https://doi.org/10.1080/00207543.2015.1081428

Martin, P. (2017). Trump, immigration, and agriculture. Choices, 32(1), 1-5.

Matopoulos, A., Vlachopoulou, M., Manthou, V., \& Manos, B. (2007). A conceptual framework for supply chain collaboration: Empirical evidence from the agri-food industry. Supply Chain Management: An International Journal, 12(3), 177-186. https://doi.org/10.1108/13598540710742491

Mazar, M., Sahnoun, M., Bettayeb, B., Klement, N., \& Louis, A. (in press). Simulation and optimisation of robotic tasks for UV treatment of diseases in horticulture. Operational Research. https://doi.org/10.1007/s12351-019-00541-w 
Duong et. al (preprint). A review of robotics and autonomous systems in the food industry: From the supply chains perspective. Trends in Food Science \& Technology. https://doi.org/10.1016/j.tifs.2020.10.028

McCarthy, U., Uysal, I., Badia-Melis, R., Mercier, S., O’Donnell, C., \& Ktenioudaki, A. (2018). Global food security - Issues, challenges and technological solutions. Trends in Food Science \& Technology, 77, 11-20. https://doi.org/10.1016/j.tifs.2018.05.002

McGee, P. (2020, May 18). Five robots that hope to save the US food supply chain. Financial Times. https://www.ft.com/content/5dced1f4-2c25-4af6-91e5-f0ac773ef3c1

Mehrjerdi, Y. Z. (2010). Coupling RFID with supply chain to enhance productivity. Business Strategy Series, 11(2), 107-123. https://doi.org/10.1108/17515631011026434

Meneghetti, A., \& Monti, L. (2015). Greening the food supply chain: An optimisation model for sustainable design of refrigerated automated warehouses. International Journal of Production $\quad$ Research, 53(21), 6567-6587. https://doi.org/10.1080/00207543.2014.985449

Miranda, J., Ponce, P., Molina, A., \& Wright, P. (2019). Sensing, smart and sustainable technologies for Agri-Food 4.0. Computers in Industry, 108, 21-36. https://doi.org/10.1016/j.compind.2019.02.002

Moher, D., Shamseer, L., Clarke, M., Ghersi, D., Liberati, A., Petticrew, M., Shekelle, P., \& Stewart, L. A. (2015). Preferred reporting items for systematic review and metaanalysis protocols (PRISMA-P) 2015 statement. Systematic Reviews, 4(1), 1-9. https://doi.org/10.1186/2046-4053-4-1

Nadal, A., Alamús, R., Pipia, L., Ruiz, A., Corbera, J., Cuerva, E., Rieradevall, J., \& Josa, A. (2017). Urban planning and agriculture. Methodology for assessing rooftop greenhouse potential of non-residential areas using airborne sensors. Science of The Total Environment, 601-602, 493-507. https://doi.org/10.1016/j.scitotenv.2017.03.214

Noone, B. M., \& Coulter, R. C. (2012). Applying modern robotics technologies to demand prediction and production management in the quick-service restaurant sector. Cornell Hospitality Quarterly, 53(2), 122-133. https://doi.org/10.1177/1938965511434112 
Duong et. al (preprint). A review of robotics and autonomous systems in the food industry: From the supply chains perspective. Trends in Food Science \& Technology. https://doi.org/10.1016/j.tifs.2020.10.028

Olsen, T. L., \& Tomlin, B. (2020). Industry 4.0: Opportunities and challenges for operations management. Manufacturing \& Service Operations Management, 22(1), 113-122. https://doi.org/10.1287/msom.2019.0796

Ortiz, D., Litvin, A. G., \& Salas Fernandez, M. G. (2018). A cost-effective and customisable automated irrigation system for precise high-throughput phenotyping in drought stress studies. PLOS ONE, 13(6), e0198546. https://doi.org/10.1371/journal.pone.0198546

Ponemon Institute,. (2011). Second annual cost of cyber crime study. Ponemon Institute. https://www.ponemon.org/local/upload/file/2011_2nd_Annual_Cost_of_Cyber_Crim e_Study\%20.pdf

Rehman, T. U., Mahmud, Md. S., Chang, Y. K., Jin, J., \& Shin, J. (2019). Current and future applications of statistical machine learning algorithms for agricultural machine vision systems. Computers and Electronics in Agriculture, 156(1), 585-605. https://doi.org/10.1016/j.compag.2018.12.006

Rodgers, S. (2008). Technological innovation supporting different food production philosophies in the food service sectors. International Journal of Contemporary Hospitality Management, 20(1), 19-34. https://doi.org/10.1108/09596110810848541

Rodias, E., Berruto, R., Busato, P., Bochtis, D., Sørensen, C. G., \& Zhou, K. (2017). Energy savings from optimised in-field route planning for agricultural machinery. Sustainability, 9(11), 1956. https://doi.org/10.3390/su9111956

Rong, A., Akkerman, R., \& Grunow, M. (2011). An optimisation approach for managing fresh food quality throughout the supply chain. International Journal of Production Economics, 131(1), 421-429. https://doi.org/10.1016/j.ijpe.2009.11.026

Rotz, S., Gravely, E., Mosby, I., Duncan, E., Finnis, E., Horgan, M., LeBlanc, J., Martin, R., Neufeld, H. T., Nixon, A., Pant, L., Shalla, V., \& Fraser, E. (2019). Automated pastures and the digital divide: How agricultural technologies are shaping labour and rural 
Duong et. al (preprint). A review of robotics and autonomous systems in the food industry: From the supply chains perspective. Trends in Food Science \& Technology. https://doi.org/10.1016/j.tifs.2020.10.028

communities. Journal of Rural Studies, 68, 112-122. https://doi.org/10.1016/j.jrurstud.2019.01.023

Sabzi, S., \& Arribas, J. I. (2018). A visible-range computer-vision system for automated, nonintrusive assessment of the $\mathrm{pH}$ value in Thomson oranges. Computers in Industry, 99, 69-82. https://doi.org/10.1016/j.compind.2018.03.016

Sanders, N. R., Boone, T., Ganeshan, R., \& Wood, J. D. (2019). Sustainable supply chains in the age of AI and digitisation: Research challenges and opportunities. Journal of Business Logistics, 40(3), 229-240. https://doi.org/10.1111/jbl.12224

Sarkis, J., Cohen, M. J., Dewick, P., \& Schröder, P. (2020). A brave new world: Lessons from the COVID-19 pandemic for transitioning to sustainable supply and production.

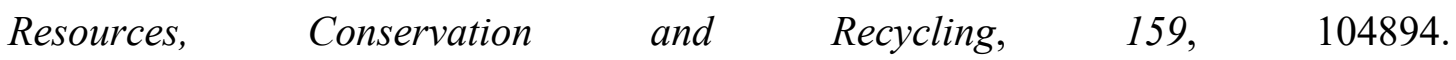
https://doi.org/10.1016/j.resconrec.2020.104894

Schanes, K., Dobernig, K., \& Gözet, B. (2018). Food waste matters-A systematic review of household food waste practices and their policy implications. Journal of Cleaner Production, 182(1), 978-991. https://doi.org/10.1016/j.jclepro.2018.02.030

Schuetz, C. G., Schausberger, S., \& Schrefl, M. (2018). Building an active semantic data warehouse for precision dairy farming. Journal of Organizational Computing and Electronic Commerce, 28(2), 122-141. https://doi.org/10.1080/10919392.2018.1444344

Serra, C. E. M., \& Kunc, M. (2015). Benefits realisation management and its influence on project success and on the execution of business strategies. International Journal of Project Management, 33(1), 53-66. https://doi.org/10.1016/j.ijproman.2014.03.011

Soosay, C. A., \& Hyland, P. (2015). A decade of supply chain collaboration and directions for future research. Supply Chain Management: An International Journal, 20(6), 613-630. https://doi.org/10.1108/scm-06-2015-0217 
Duong et. al (preprint). A review of robotics and autonomous systems in the food industry: From the supply chains perspective. Trends in Food Science \& Technology. https://doi.org/10.1016/j.tifs.2020.10.028

Sterman, J., Oliva, R., Linderman, K., \& Bendoly, E. (2015). System dynamics perspectives and modeling opportunities for research in operations management. Journal of Operations Management, 39-40(1), 1-5. https://doi.org/10.1016/j.jom.2015.07.001

Stone, J., \& Rahimifard, S. (2018). Resilience in agri-food supply chains: A critical analysis of the literature and synthesis of a novel framework. Supply Chain Management: An International Journal, 23(3), 207-238. https://doi.org/10.1108/scm-06-2017-0201

Sun, J., Zhou, W., Huang, D., Fuh, J. Y. H., \& Hong, G. S. (2015). An overview of 3D printing technologies for food fabrication. Food and Bioprocess Technology, 8(8), 1605-1615. https://doi.org/10.1007/s11947-015-1528-6

Suprem, A., Mahalik, N., \& Kim, K. (2013). A review on application of technology systems, standards and interfaces for agriculture and food sector. Computer Standards \& Interfaces, 35(4), 355-364. https://doi.org/10.1016/j.csi.2012.09.002

Tan, S. Y., \& Taeihagh, A. (2020). Smart city governance in developing countries: A $\begin{array}{lllll}\text { systematic } & \text { literature } & \text { review. } & \text { Sustainability, } & 12(3),\end{array}$ https://doi.org/10.3390/su12030899

Terazono, E. (2018, December 10). The billion-dollar agritech start-ups disrupting farming. Financial Times. https://www.ft.com/content/ee6fb294-edc3-11e8-8180$9 \mathrm{cf} 212677 \mathrm{a} 57$

Tidy, J. (2019, June 25). How a ransomware attack cost one firm £45m. BBC News. https://www.bbc.com/news/business-48661152

Tiotsop, L. F., Servetti, A., \& Masala, E. (2020). An integer linear programming model for efficient scheduling of UGV tasks in precision agriculture under human supervision. Computers $\quad$ Operations $\quad$ Research, $114, \quad 104826$. https://doi.org/10.1016/j.cor.2019.104826 
Duong et. al (preprint). A review of robotics and autonomous systems in the food industry: From the supply chains perspective. Trends in Food Science \& Technology. https://doi.org/10.1016/j.tifs.2020.10.028

Tranfield, D., Denyer, D., \& Smart, P. (2003). Towards a methodology for developing evidence-informed management knowledge by means of systematic review. British Journal of Management, 14(3), 207-222. https://doi.org/10.1111/1467-8551.00375

Trivelli, L., Apicella, A., Chiarello, F., Rana, R., Fantoni, G., \& Tarabella, A. (2019). From precision agriculture to Industry 4.0: Unveiling technological connections in the agrifood sector. British Food Journal, 121(8), 1730-1743. https://doi.org/10.1108/bfj$11-2018-0747$

Tsakanikas, P., Pavlidis, D., \& Nychas, G.-J. (2015). High throughput multispectral image processing with applications in food science. PLoS ONE, 10(10), e0140122. https://doi.org/10.1371/journal.pone.0140122

United Nations. (2018, May 16). 68\% of the world population projected to live in urban areas by 2050, says UN. United Nations Department of Economic and Social Affairs. https://www.un.org/development/desa/en/news/population/2018-revision-of-worldurbanization-prospects.html

van der Vorst, J. G. A. J., Tromp, S. O., \& van der Zee, D.-J. (2009). Simulation modelling for food supply chain redesign; integrated decision making on product quality, sustainability and logistics. International Journal of Production Research, 47(23), 6611-6631. https://doi.org/10.1080/00207540802356747

Vandeplas, A., Minten, B., \& Swinnen, J. (2013). Multinationals vs. cooperatives: The income and efficiency effects of supply chain governance in india. Journal of Agricultural Economics, 64(1), 217-244. https://doi.org/10.1111/1477-9552.12004

von Borstel Luna, F. D., de la Rosa Aguilar, E., Naranjo, J. S., \& Jagüey, J. G. (2017). Robotic system for automation of water quality monitoring and feeding in aquaculture shadehouse. IEEE Transactions on Systems, Man, and Cybernetics: Systems, 47(7), 1575-1589. https://doi.org/10.1109/tsmc.2016.2635649 
Duong et. al (preprint). A review of robotics and autonomous systems in the food industry: From the supply chains perspective. Trends in Food Science \& Technology. https://doi.org/10.1016/j.tifs.2020.10.028

Wolfert, S., Ge, L., Verdouw, C., \& Bogaardt, M.-J. (2017). Big data in smart farming - A review. Agricultural Systems, 153, 69-80. https://doi.org/10.1016/j.agsy.2017.01.023

World Economic Forum. (2020). The global risks report 2020. https://www.weforum.org/reports/the-global-risks-report-2020

Zhao, G., Liu, S., Lopez, C., Lu, H., Elgueta, S., Chen, H., \& Boshkoska, B. M. (2019). Blockchain technology in agri-food value chain management: A synthesis of applications, challenges and future research directions. Computers in Industry, 109, 8399. https://doi.org/10.1016/j.compind.2019.04.002

Zhong, R., Xu, X., \& Wang, L. (2017). Food supply chain management: Systems, implementations, and future research. Industrial Management \& Data Systems, 117(9), 2085-2114. https://doi.org/10.1108/imds-09-2016-0391 